\title{
ALGUNS ASPECTOS DA BIOLOGIA DE BIOMPHALARIA GLABRATA (SAY, 1818) E BIOMPHALARIA TENAGOPHILA (D'ORBIGNY, 1835) (PULMONATA, PLANORBIDAE). II - FECUNDIDADE E FERTILIDADE *
}

\begin{abstract}
KAWAZoE, U. Alguns aspectos $d a$ biologia de Biomphalaria glabrata (Say, 1818) e Biomphalaria tenagophila (D'Orbigny, 1835) (Pulmonata, planorbidae). II - Fecundidade e fertilidade. Rev. Saúde públ., S. Paulo, 11: 47-64, 1977.

RESUMo: Foi realizada, comparativamente, a avaliação do número de cápsulas ovíferas e ovos por caramujo e do numero de ovos por desova (fecundidade) e a verificação da taxa de eclosão e de ovos férteis (fertilidade) de Biomphalaria glabrata e Biomphalaria tenagophila, no periodo de um ano, em condiçōes de laboratório. Verificou-se que a média do número de ovos por desova foi significativamente maior em B. glabrata (19,9) do que em B. tenagophila (16,2), constatando-se que ambas as espécies apresentavam maior fecundidade no mês de abril, embora os fatores ambientes tenham influido pouco no parâmetro em questão. A fecundidade traduzida pelo número de desovas por caramujo-dia, mostrou-se maior em B. glabrata $(0,65)$ do que em B. tenagophila $(0,56)$, o mesmo acontecendo em relação ao numero de ovos por caramujo-dia pois $\mathrm{B}$. glabrata apresentou média de 13,4 e $\mathrm{B}$. tenagophila média de 9,9. Considerando-se a fertilidade como a percentagem de eclosão dos caramujos, B. glabrata apresentou média de $95,8 \%$ e B. tenagophila a média de $90,5 \%$ de eclosão, sendo esta diferença significativa ao nivel de $5 \%$. As taxas mais elevadas de eclosão em B. glabrata foram verificadas nos meses de nomais elevadas de eclosão em B. glabrata foram verificadas nos meses de novembro a janeiro (98,0\%) e em B. tenagophila nos meses outubro-novembro $(95,0 \%)$ embora não tenham sido observados ritmo sazonal nem influência da temperatura na eclosão dos planorbideos estudados.
\end{abstract}

Unitermos: Planorbideos, biologia. Biomphalaria glabrata. Biomphalaria tenagophila. Fecundidade. Fertilidade.

\section{INTRODUC $\mathrm{T} O$}

Prosseguindo com o estudo biológico comparado entre os planorbídeos $B$. glabrata e B. tenagophila (Kawazoe ${ }^{5}, 1976$ ), propomos neste trabalho, observações referentes a fecundidade (avaliação do nú- mero de cápsulas ovíferas e ovos por caramujo e do número de ovos por desova) e a fertilidade (taxa de eclosão dos caramujos e proporção de ovos férteis e não férteis) dessas populações.

* Trabalho realizado, em parte, com o auxilio da FAPESP, CNPq e CAPES, em diferentes etapas da pesquisa.

* Do Departamento de Parasitologia da Universidade de Campinas (UNICAMP) - $13100-$ Campinas, SP - Brasil. 
KAWAZOE, U. - Alguns aspectos da biologla de Biomphalaria glabrata (Say, 1818) e Biomphalaria tenagophila (D'Orbigny, 1835) (Pulmonata, planorbidae). II - Fecundidade e fertilidade. Rev. Saúde públ., S. Paulo, 11:47-64, 1977.

Apesar desses estudos terem sido realizados por vários pesquisadores, principalmente em relação à espécie $B$. glabrata, sabe-se muito pouco a respeito do comportamento biológico, tanto em laboratório como no seu habitat natural, da espécie $B$. tenagophila.

\section{MATERIAL E MÉTODOS}

Basicamente, foi empregado o mesmo método utilizado no trabalho anterior ( $\mathrm{Ka}$ wazoe ${ }^{5}$. 1976) para a criação dos planorbídeos. As observações foram realizadas com as mesmas populações de caramujos, isto é, $B$. glabrata de Salvador, Bahia e B. tenagophila de Campinas. São Paulo.

Para a verificação da fecundidade foi realizada contagem diária de cápsulas ovíferas e ovos à lupa estereoscópica. Foram computadas, também, as desovas encontradas nas paredes dos frascos. As oviposições efetuadas na superfície das conchas eram retiradas e colocadas em frasco "becker" de $250 \mathrm{ml}$, onde eram contados o número de ovos e observados até o momento da eclosão.

Os plásticos colocados na superfície da água, repletos de desovas, eram retirados e transferidos para um "becker" de 250 $\mathrm{ml}$ para verificação e contagem dos caramujos eclodidos. A seguir, um novo plástico era depositado no frasco original onde o par de caramujos continuava a oviposição.

A fertilidade dos ovos foi avaliada através da taxa de eclosão dos caramujos e pela percentagem de ovos férteis. A taxa de eclosão foi verificada pela contagem de exemplares eclodidos e não eclodidos, observação esta realizada à lupa estereoscópica. Por outro lado, foram considerados ovos férteis aqueles que apresentavam massa embrionária viva ou degenerada.
Foram utilizados os mesmos dados registrados no trabalho anterior, quanto aos fatores ambientes, isto é, temperatura máxima e nínima do ambiente, temperatura da água e pressão atmosférica.

\section{RESULTADOS}

\subsection{Fecundidade}

\subsubsection{Número de Oros por Cápsula Ovífera}

A freqüência média de ovos por cápsula ovífera foi de 19.9 em $B$. glabrata e 16.2 em B. tenagophila (Tabela 1).

A análise da variância testada dentro de cada população, separadamente, mostrou que o número de ovos por cápsula ovífera variou significativamente, nos 11 períodos, em cada espécie estudada. Deste modo, procedeu-se a comparação entre as duas espécies, período por período, utilizando o teste " $t$ ", com a obtenção dos resultados assinalados na Tabela 2 .

$O$ teste revelou que, com exceção dos períodos 1. 2 e 9, o número de ovos por cápsula ovífera diferiu significativamente nas duas populações, ao nível de $5 \%$.

Por outro lado, foi analisado o grau de associação existente entre os fatores ambientes e a variável em questão, para ambas as espécies, através da matriz de correlação (Tabela 3). Verificou-se fraca correlação entre a média de ovos por desova de $B$. glabrata e os fatores ambientes, porém, a correlação foi maior entre aquela variável referente a $B$. tenagophila e a temperatura máxima $(46,3 \%)$. A mesma variâvel apresentou fraca correlação com a temperatura mínima, temperatura da água e com a pressão atmosférica.

A Figura 1 apresenta a comparação dos números médios de ovos por desova entre as duas populações relacionados com a temperatura ambiente e com a da água. 
KAWAZOE, U. - Alguns aspectos da biologia de Biomphalaria glabrata (Say, 1818) e Biomphalaria tenagophila (D'Orbigny, 1835) (PuImonata, planorbidae). II - Fecundidade e fertilidade. Rev. Saúde publ., S Paulo, 11:47-64, 1977.

TA B E L A 1

Número médio de ovos por cápsula ovífera de $B$. glabrata e $B$. tenagophlla. em periodos de 20 dias de observação

\begin{tabular}{|c|c|c|c|c|c|c|}
\hline \multirow{2}{*}{ Períodos de observaçāo } & \multicolumn{3}{|c|}{ B. glabrata } & \multicolumn{3}{|c|}{ B. tenagophila } \\
\hline & $n *$ & $\overrightarrow{\mathrm{x}}$ & $s$ & $n *$ & $\overline{\mathrm{X}}$ & $s$ \\
\hline \multicolumn{7}{|l|}{10} \\
\hline $\begin{array}{c}(13-03-69 \text { a } \\
2 .^{\circ}\end{array}$ & 500 & 21,5 & 8,82 & 392 & 22,3 & 8,75 \\
\hline $\begin{array}{c}(15-04-69 \text { a } \\
3.0^{04-05-69)}\end{array}$ & 327 & 25,6 & 10,18 & 262 & 24,1 & 8,04 \\
\hline $\begin{array}{c}(22-05-69 \text { a } 10-06-69) \\
4.0\end{array}$ & 348 & 20.7 & 6,76 & 264 & 19.5 & 7.29 \\
\hline $\begin{array}{c}(26-06-69 \text { a } 15-07-69) \\
5.0^{\circ}\end{array}$ & 326 & 19.4 & 6,54 & 243 & 13.3 & 6,28 \\
\hline $\begin{array}{c}(07-08-69 \text { a } 26-08-69) \\
6.0^{\circ}\end{array}$ & 318 & 20,8 & 9,11 & 330 & 15,2 & 5,35 \\
\hline $\begin{array}{c}(13-09-69 \text { a } 02-10-69) \\
7 .^{\circ}\end{array}$ & 371 & 17,1 & 6.43 & 323 & 12,0 & 4,66 \\
\hline $\begin{array}{c}(16-10-69 \text { a } 04-11-69) \\
8 .^{\circ}\end{array}$ & 347 & 18,1 & 7,69 & 276 & 11,7 & 4,56 \\
\hline $\begin{array}{c}(17-11-69 \text { a } \\
90^{0}\end{array}$ & 286 & 17,9 & 8,39 & 165 & 8,8 & 5,12 \\
\hline $\begin{array}{c}(24-12-69 \text { a } 12-01-70) \\
10^{\circ}\end{array}$ & 265 & 17,2 & 7,18 & 280 & 16,8 & 9,25 \\
\hline $\begin{array}{c}(28-01-70 \text { a } 16-02-70) \\
11.0^{\circ}\end{array}$ & 253 & 21,9 & 5,99 & 243 & 13,9 & $\mathbf{5}, 46$ \\
\hline$(03-03-70$ a $22-03-70)$ & 312 & 18.1 & $6,4 \mathrm{~S}$ & 267 & 15,6 & 6,67 \\
\hline Total & 3653 & 一 & - & 3045 & - & - \\
\hline Média geral & - & 19.9 & 7.60 & - & 16.2 & 6,49 \\
\hline
\end{tabular}

* Número total de cápsulas oviferas observadas.

\subsubsection{Número de Cápsulas Otíferas e Oros por Caranuijo}

Foi obtida média de 12.8 cápsulas ovíferas e 258.1 ovos por caramujo nos exemplares $B$. glabrata enquanto $B$. tenagophila apresentou média de 10.8 desovas e 175.6 ovos por caramujo. em 20 dias, nos 11 períodos estudados (Tabela 4 ).

Observou-se, também, que cada caramujo $B$. glabrata ovipôs, em média, 0,64 desoras e 12.9 oros por dia e $B$. tena- gophila apresentou a média de 0.54 desovas e 8.8 ovos por dia (Tabela 7 ).

Para efeito de cálculo estatístico das rariáreis em questão inúmero de desovas e ovos por caramujo), como primeira aproximação foi suposto que as variáveis. em cada uma das espécies. apresentavam distribuição de Poisson. Foram comparadas as 11 observaçōes da variável aleatória de Poisson, dentro de cada espécie, a fim de testar a existência da variação em cada população. O resultado mostrou que em 
KAWAZOE, U. - Alguns aspectos da biologia de Biomphalaria glabrata (Say, 1818) e Biomphalaria tenagophila (D'Orbigny, 1835) (Pulmonata, planorbidae). II - Fecundidade e fertilidade. Rev. Saúde públ., S. Paulo, 11:47-64, 1977.

\section{T A B E A 2}

Teste " $t$ " realizado entre nûmero médio de ovos por desova de $B$. glabrata e $B$. tenago. phila, em cada periodo de observação

\begin{tabular}{|c|c|}
\hline Periodos & "t" \\
\hline 1.0 & $-1,35$ \\
\hline 2.0 & 1,95 \\
\hline $3 .{ }^{\circ}$ & $2,10^{*}$ \\
\hline $4 .^{\circ}$ & $11,01 *$ \\
\hline 5.0 & $9,58 *$ \\
\hline $60^{\circ}$ & 11,81 * \\
\hline $70^{\circ}$ & 12,22 * \\
\hline $8 .^{\circ}$ & 12,64 * \\
\hline $90^{\circ}$ & 0,56 \\
\hline $10 .^{\circ}$ & $15,53^{*}$ \\
\hline $11 .^{\circ}$ & $4,57 \%$ \\
\hline
\end{tabular}

* significância ao nível de $5 \%$ ambas as espécies houve variação significativa entre os periodos, tanto para o número de desovas como para o número de ovos.

Em decorrência dos resultados obtidos por esses cálculos preliminares, procedeuse ao teste de hipótese, comparando as duas espécies, período por período, como se pode verificar na Tabela 5 .

A comparação entre as médias do número de cápsulas ovíferas por caramujo das duas populações mostrou diferença significativa em 6 periodos e a proporção apresentou-se praticamente igual nos periodos 5, 6, 9, 10 e 11 .

A média do número de ovos por caramujo em $B$. glabrata e $B$. tenagophila apresentou diferença significativa ao nível de $5 \%$. em todos os períodos, exceto no 9. .

TABELA 3

Coeficiente de correlação entre fatores ambientes e número médio de ovos por desova de B. glabrata e $B$. tenagophila

\begin{tabular}{c|c|c} 
Fatores ambientes & B. glabrata & B. tenagophila \\
\hline \hline Temperatura máxima média & 0,030 & 0,463 \\
Temperatura mínima média & $-0,214$ & $-0,072$ \\
Temperatura média da água & $-0,166$ & 0,109 \\
Pressão atmosférica média & 0,228 & 0,270 \\
\hline
\end{tabular}

A matriz de correlação entre o número de ovos por caramujo e os fatores ambientes apresentou os resultados contidos na Tabela 6. B. glabrata mostrou fraca correlação com os fatores ambientes. Em $B$. tenagophila verificou-se fraca correlação entre o número de ovos por caramujo e fatores ambientes, exceto em relação a temperatura máxima que apresentou $45 \%$ de correlação.

A Figura 2 apresenta os dados comparados de $B$. glabrata e $B$. tenagophila em relação ao número de cápsulas oviferas por caramujo, em cada período estudado. Os dados sobre temperatura ambiente e temperatura da água também encontram-se relacionados. 


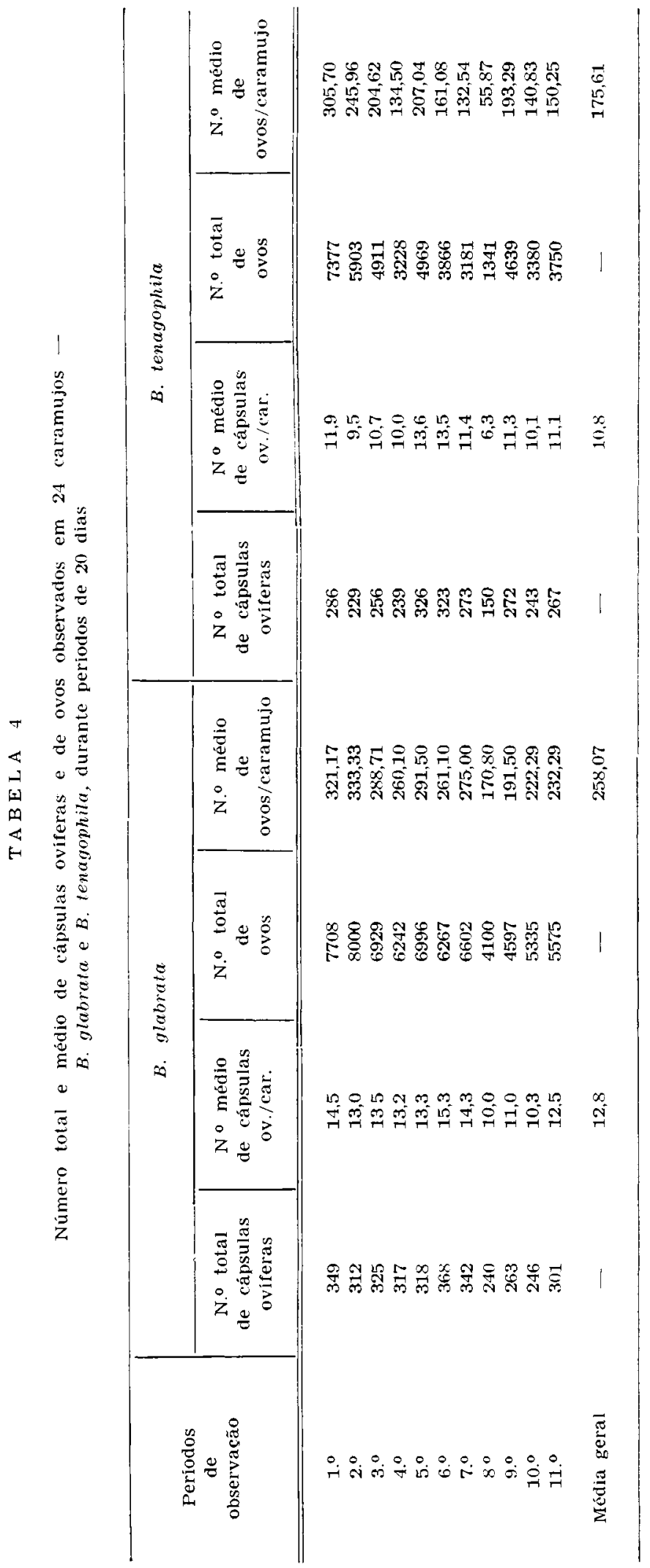


KAWAZOE, U. - Alguns aspectos da biologia de Biomphalaria glabrata (Say, 1818) e Biomphalaria tenagophila (D'Orbigny, 1835) (Pulmonata, planorbidae). II — Fecundidade e fertilidade. Rev. Saúde públ., S. Paulo, 11:47-64, 1977.

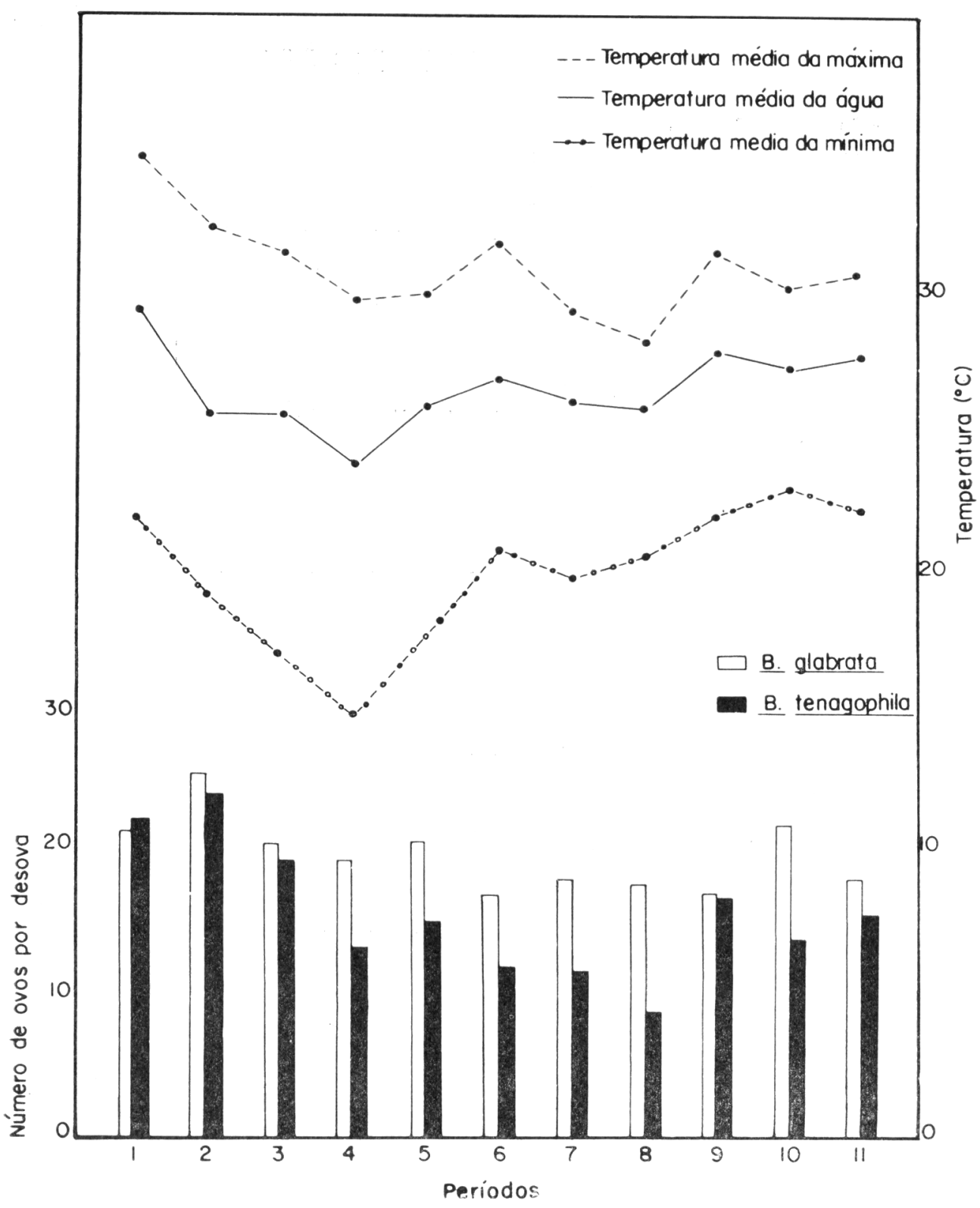

Fig. 1 - Comparacão do número de ovos por desova entre B. glabrata e $B$. tenagophila e sua relação com as temperaturas do ar e da água. 
KAWAZOE, U. - Alguns aspectos da biologia de Biomphalaria glabrata (Say, 181s) e Biomphalaria tenagophila (D'Orbigny, 1835) (Pulmonata, planorbidae). II - Fecundidade e fertilidade. Rev. Saude publ., S. Paulo, 11:47-64, 1977.

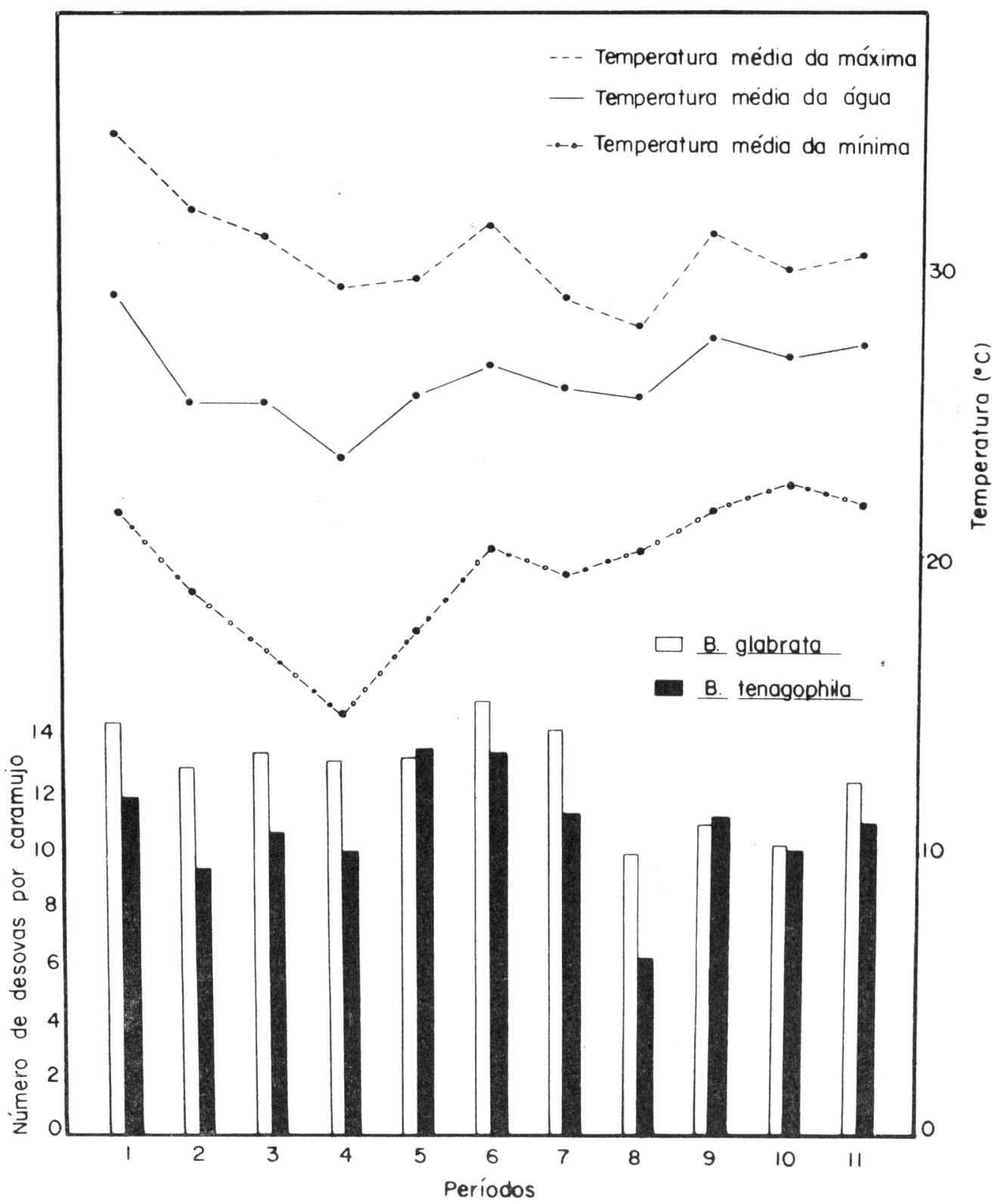

Fig. 2 - Número médio de desovas, em 20 dias, por caramujo de B. glabrala e B. tenagophlla e sua relasaão com as temperaturas do ar e da água 
KAWAZOE, U. - Alguns aspectos da biologia de Biomphalaria glabrata (Say, 1818) e Biomphalaria tenagophila (D'Orbigny, 1835) (Pulmonata, planorbidae). II - Fecundidade e fertilidade. Rev. Saúde públ., s. Paulo, 11:47-64, 1977.

\section{TABLA 5}

Teste de hipótese do número de cápsulas oviferas e de ovos por caramujo, testados periodo por período, entre $B$. glabrata e $B$, tenagophila

\begin{tabular}{|c|c|c|}
\hline Periodos & N.o de desovas & N.o de ovos \\
\hline $1 .^{\circ}$ & $2,46 *$ & $2,70 *$ \\
\hline $2 .^{\circ}$ & 2,66 *: & 17,76 * \\
\hline $3 .{ }^{\circ}$ & 2,82 & $18,52 *$ \\
\hline $4 .^{\circ}$ & $3,27 *$ & 30,96 * \\
\hline 5.0 & $-0,36$ & $18,52 *$ \\
\hline $6 .^{\circ}$ & 1,67 & 23,84 * \\
\hline $7.0^{\circ}$ & $2,74 *$ & 34,58 * \\
\hline $8 .^{\circ}$ & $4,51 *$ & $37,40 *$ \\
\hline 9.0 & -0.43 & $-0,45$ \\
\hline 10.0 & 0,09 & 20,93 * \\
\hline 11.0 & 1,39 & $18,90 *$ \\
\hline
\end{tabular}

* significância ao nivel de $5 \%$

\subsection{Fertilidade: Taxa de eclosão e} percentagem de ovos férteis

Os exemplares $B$. glabrata apresentaram média percentual de $94,8 \%$ e $B$. tenagophila $90,5 \%$ de caramujos eclodidos (Tabela 8).

Foi testada a diferença de proporções nos 11 períodos, dentro de cada espécie, verificando-se diferença significativa entre elas. Deste modo, foi aplicado o "teste de igualdade de duas proporções" entre as espécies, por período, notando-se que apenas no $7 .^{\circ}$ período não houve diferença significativa ao nivel de $5 \%$ (Tabela 9).

Por outro lado, foi calculada a matriz de correlação entre a temperatura máxima, minima, temperatura da água, pressão atmosférica e a percentagem de ca-

TA B E L A 6

Coeficiente de correlação entre número de ovos por caramujo em B. glabrata e $B$. tenagophila e os fatores ambientes

\begin{tabular}{l|rr} 
Fatores ambientes & B. glabrata & B. tenagophila \\
\hline Temperatura máxima média & 0,014 & 0,451 \\
Temperatura minima média & $-0,206$ & $-0,060$ \\
Temperatura média da água & $-0,163$ & 0,116 \\
Pressão atmosférica média & 0,207 & 0,256 \\
\end{tabular}

ramujos eclodidos, tanto de $B$. glabrata como de $B$. tenagophila (Tabela 10 ). Verificou-se que houve fraca correlação entre a variável estudada e os fatores ambientes em ambas as espécies. A correlação de coeficiente mais alto foi entre a taxa de eclosão de $B$. tenagophila e a temperatura média da água $(29,0 \%)$.

A representação gráfica da percentagem de eclosão dos caramujos $B$. glabrata e B. tenagophila relacionados com as temperaturas ambientes e da água encontramse na Figura 3.

A fertilidade dos vos, expressa na forma de percentagem de ovos férteis, foi bastante grande pois foram obtidas médias de $99,5 \%$ para $B$. glabrata e $99,4 \%$ para $B$. tenagophila, nos 11 períodos de observação. 
KAWAZOE, U. - Alguns aspectos da bjologia de Biomphalaria glabrata (Say, 1818) e Biomphalaria tenagophila (D'Orbigny, 1835) (Pulmonata, planorbidae). II - Fecundidade e fertilidade. Rev. Saúde públ., S. Paulo, 11:47-64, 1977.

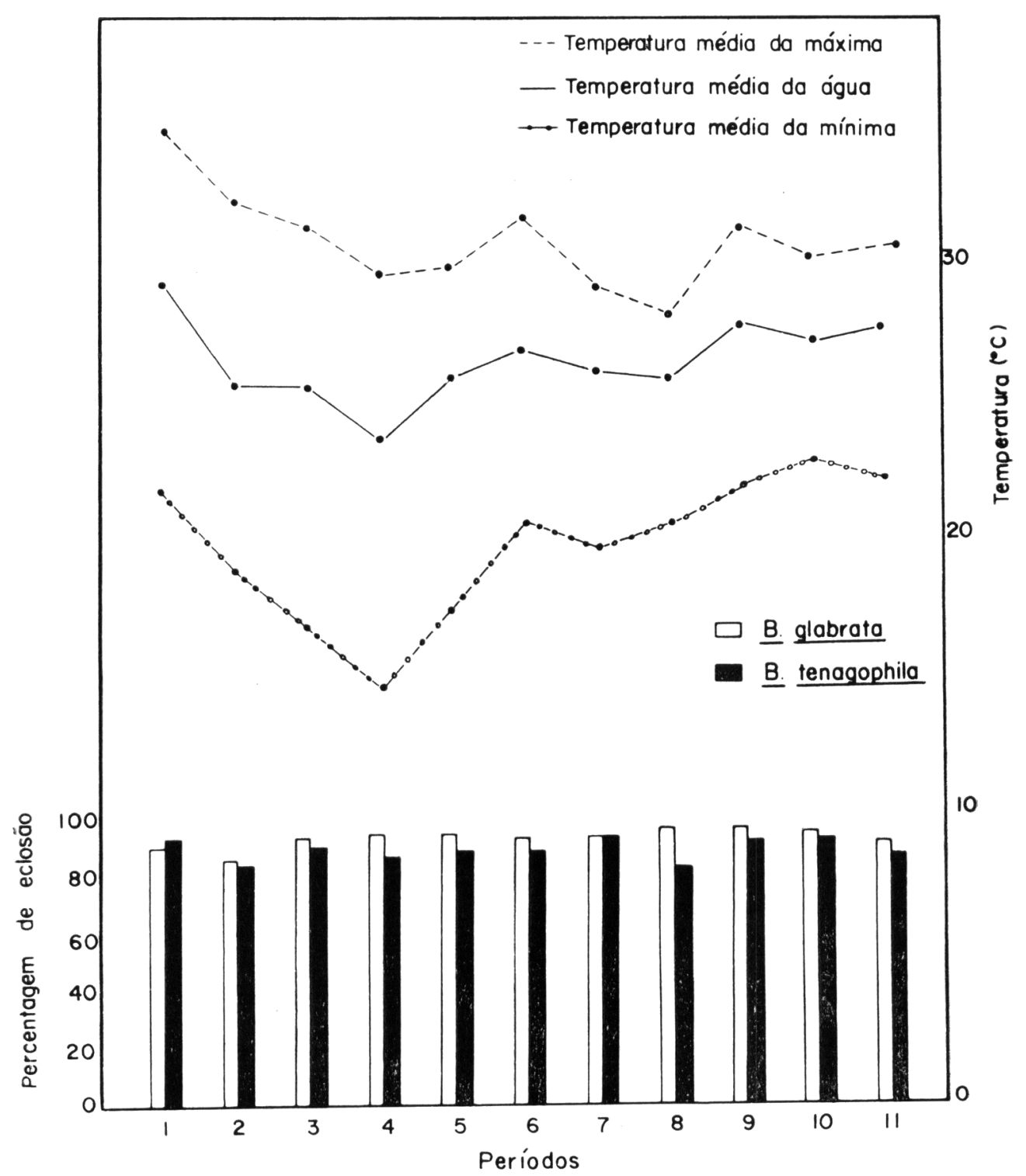

Fig. 3 - Percentagem de eclosão de $B$. glabrata e B. tenagophila e sua relacão com as temperaturas do ar e da água. 
KAWAZOE, U. - Alguns aspectos da biologia de Biomphalaria glabrata (Say, 1818) e Biomplialaria tenagophila (D'Orbigny, 1835) (Pulmonata, planorbidae). II - Fecundidade e fertilidade. Rev. Saúde públ., S. Paulo, 11:47-64, 1977.

\section{T A B ELA 7}

Número médio de cápsulas oviferas e de ovos obtidas de 24 caramujos - B. glabrata e B. tenagophita, em 24 horas

\begin{tabular}{|c|c|c|c|c|}
\hline \multirow{2}{*}{$\begin{array}{c}\text { Periodos } \\
\text { de } \\
\text { observaçāo }\end{array}$} & \multicolumn{2}{|c|}{ B. glabrata } & \multicolumn{2}{|c|}{ B. tenagophila } \\
\hline & $\begin{array}{c}\text { Cápsulas } \\
\text { oviferas/ } \\
\text { caramujo-dia }\end{array}$ & $\begin{array}{l}\text { Ovos por } \\
\text { caramujo-dia }\end{array}$ & $\begin{array}{l}\text { Cápsulas } \\
\text { ovíferas } \\
\text { caramujo-dia }\end{array}$ & $\begin{array}{c}\text { Ovos por } \\
\text { caramujo-dia }\end{array}$ \\
\hline $10^{\circ}$ & 0,72 & 16,0 & 0,59 & 15,3 \\
\hline $2^{\circ}$ & 0,65 & 16,7 & 0,47 & 12,3 \\
\hline $30^{\circ}$ & 0,67 & 14,0 & 0,53 & 10,2 \\
\hline $4 .^{\circ}$ & 0,66 & 13,0 & 050 & 6,7 \\
\hline $5 .^{\circ}$ & 0,66 & 14,5 & 0,68 & 10,4 \\
\hline $60^{\circ}$ & 0,76 & 13,5 & 0,67 & 8,1 \\
\hline 7.0 & 0.71 & 13.8 & 0,57 & 6,6 \\
\hline $8.0^{\circ}$ & $0, \Xi 0$ & 8,5 & 0,31 & 2,8 \\
\hline $90^{\circ}$ & 0,55 & 9,6 & 0,56 & 9,7 \\
\hline $10^{\circ}$ & 0,51 & 11,1 & 0,50 & 7,0 \\
\hline $110^{\circ}$ & 0,62 & 11,6 & 0,55 & 7,5 \\
\hline Média geral & 0,65 & 13,4 & 0,56 & 9,9 \\
\hline
\end{tabular}

Devido a diferença desprezível das médias percentuais verificadas nas duas populaçóes foi desnecessário o cálculo estatístico para testar a diferença entre elas.

Por outro lado. o teste de correlação entre fatores ambientes e a fertilidade dos ovos apresentou coeficientes muito baixos, significando que não houve influência de fatores ambientes sobre o parâmetro em questão.

\section{COMIENTARIOS E CONCLUSÕES}

\subsection{Fecundidade}

\subsubsection{Número de Ovos por Desolci}

A média do número de oros por desova de exemplares $B$. glabrata, que se encontra na Tabela l, mostrou concordância com resultados obtidos por Rey ${ }^{13}$ (1956). Perlowagora ${ }^{14}$ (1958) e Maga- lhães \& cols. ${ }^{6}$ (1968 e 1969). Por outro lado, a média de oros por cápsula ovífera obtida em $B$. tenagophila foi semelhante aos resultados observados por Magalhães \& cols. ${ }^{6,-}(1968$ e 1969$)$ e Milward de Andrade \& Carvalho ${ }^{10}$ (1972), tendo sido inferior a média assinalada por Rey ${ }^{16}$ (1956).

Dos autores acima citados, apenas Perlowagora trabalhou com um par de caramujos por frasco. sendo semelhante à técnica empregada neste trabalho. Entretanto, outros autores citados, utilizando métodos diferentes, alcançaram resultados similares ao encontrado neste trabalho.

Lim dos fatores que pode interferir no número de posturas dos planorbídeos refere-se ao número de espécimens encerrados num aquário. Nos exemplares mantidos agrupados observou-se menor número de ovos em frascos que continham maior quantidade de planorbídeos, poden- 
KAWAZOE, U. - Alguns aspectos da biologia de Biomphalaria glabrata (Say, 1818) e Biomphalaria tenagophila (D'Orbigny, 1835) (Pulmonata, planorbidae). II - Fecundidade e fertilidade. Rev. Saúde públ., S. Paulo, 11:47-64, 1977.

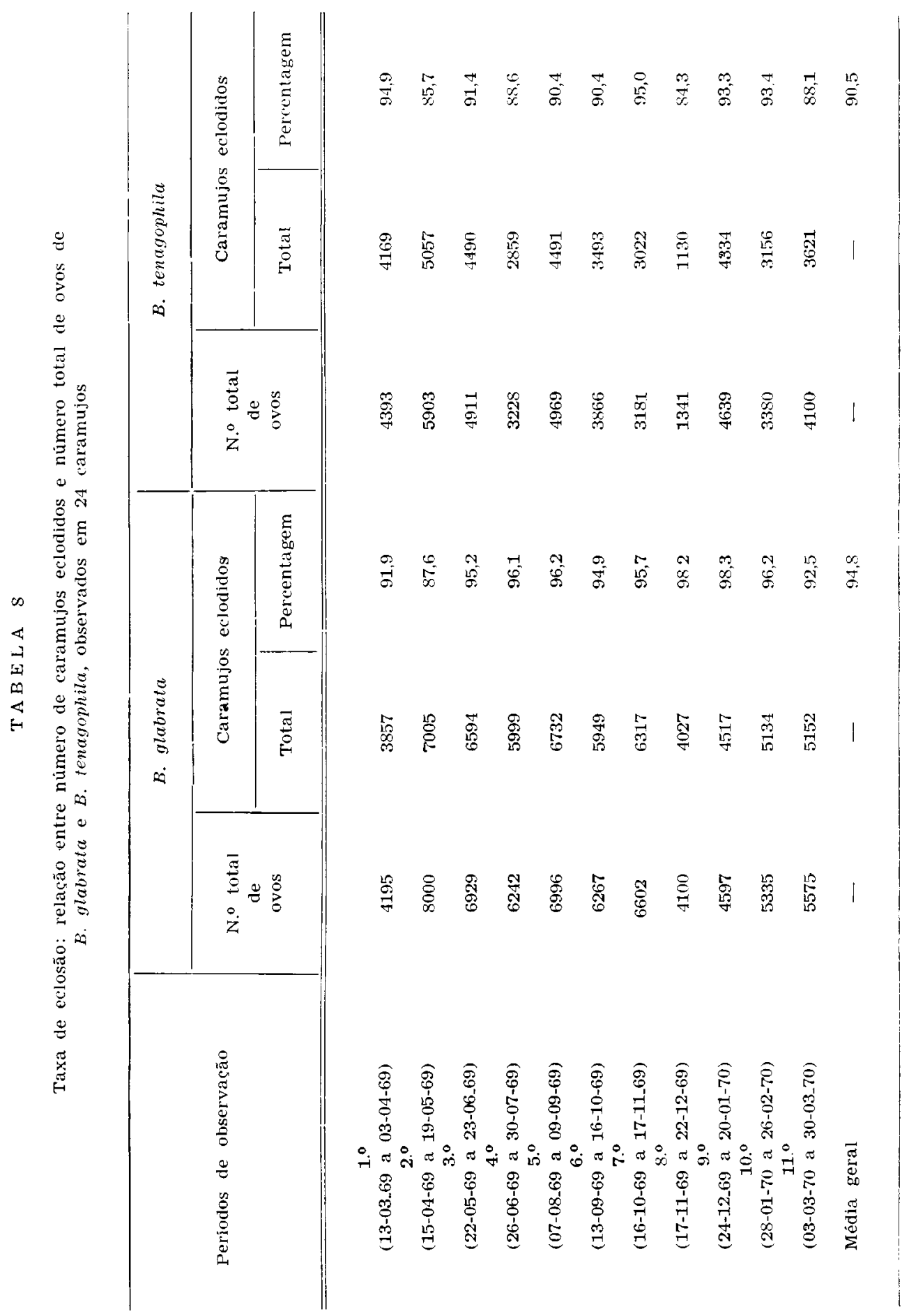


KAWAZOE, U. - Alguns aspectos da biologia de Blomphalaria glabrata (Say, 1818) e Biomphalaria tenagophila (D'Orbigny, 1835) (Pulmonata. planorbidae). II - Fecundidade e fertilidade. Rev. Saude públ., S. Paulo, 11:47-64, 1977.

\section{TA B E A 9}

Teste de igualdade de duas proporcōes realizado periodo por período entre taxa de eclosão de $B$. glabrata e $B$. tenagophila.

\begin{tabular}{|c|c|}
\hline Periodos & Coeficiente $z$ \\
\hline 1.0 & $5,92 *$ \\
\hline 2.0 & $-3,17$ * \\
\hline $3.0^{\circ}$ & $7,48 *$ \\
\hline $4 .^{\circ}$ & $14,23 *$ \\
\hline 5.0 & 12,72 \\
\hline $6.0^{\circ}$ & $8,81 *$ \\
\hline 7.0 & 1,48 \\
\hline $8^{\circ}$ & $19,93 *$ \\
\hline $9.0^{\circ}$ & $12,00 *$ \\
\hline $10 .^{\circ}$ & $6,36 *$ \\
\hline $11 .^{\circ}$ & $7,28 *$ \\
\hline
\end{tabular}

* significància ao nivel de $5 \%$ do estar presente, neste caso, o efeito da densidade populacional. $\mathrm{O}$ menor número foi verificado em caramujos mantidos isolados e o maior quando um par de caramujos foi colocado num mesmo fraco. Perlowagora ${ }^{1.1}$ (1958) encontrou média de 8 a 11.2 ovos por desova em $B$. glabrata pareados, enquanto nos isolados encontrou média de 5.8 a 7,2 ovos por desova; Barreto ${ }^{1}$ (1960) encontrou 5 e 7.5 ovos por desova respectivamente em $B$. glabrata isolados e pareados. Por outrc lado, Ritchie \& cols. ${ }^{17}$ (1966) obtiveram 38 e 50 ovos por desova em $B$. glabrata mantidos isolados e pareados, respectivamente. Brumpt" (1941) observou o oposto, pois obteve maior número de posturas em animais mantidos isolados.

Alguns autores verificaram que o tamanho dos moluscos influía sobre o nú-

TA B E A 10

Coeficiente de correlação entre percentagem de eclosão dos caramujos $B$. glabrata e $B$. tenagophila e os fatores ambientes

\begin{tabular}{l|c|c}
\hline Fatores ambientes & B. glabrata & B. tenagophila \\
\hline \hline Temperatura máxima média & $-0,17$ & 0,27 \\
Temperatura minima média \\
Temperatura média da água
\end{tabular}

mero médio de ovos por desova, sendo que a partir da maturidade sexual havia aumento progressivo desse número, conforme o crescimento das conchas. Jan$\operatorname{sen}^{4}$ (1944) encontrou 45 ovos por desova em caramujos B. glabrata com 20 mm de diâmetro máximo; Rey ${ }^{16}$ (1956) obteve média de 24,$5 ; 32,1$ e 59.5 ovos por desova respectivamente em $B$, glabrata medindo 13,$0 ; 17,0$ e $24,0 \mathrm{~mm} ; \mathrm{Pi}-$ mentel $^{15}$ (1957) obteve média de $10,6 \mathrm{e}$ 28,1 ovos por desova em $B$. glabrata medindo, respectivamente, 8,4 e $19,3 \mathrm{~mm}$ de diâmetro e Michelson ${ }^{9}$ (1961) observou média de 16,9 ovos por desova em $B$. glabrata com $4,8 \mathrm{~mm}$ de diâmetro máximo. No nosso trabalho foi obtida média de 19.9 ovos por desova utilizando exemplares entre 8 a $11 \mathrm{~mm}$ de diâmetro máximo. Cada autor citado verificou em seus trabalhos que havia aumento do número de posturas em exemplares maiores, porém. analisando-se o conjunto de dados notase que pode haver outros fatores influindo no desenvolvimento desses planorbídeos. Penido \& cols. ${ }^{13}$ (1951) observa- 
KAWAZOE, U. - Alguns aspectos da biologia de Blomphalaria glabrata (Say, 1818) e Biomphalaria tenagophila (D'Orbigny, 1835) (Pulmonata, planorbidae). II - Fecundidade e fertilidade. Rev. Saúde públ., S Paulo, 11:47-64, 1977.

ram que havia diferença no número de ovos por desova, numa mesma população de $B$. glabrata, quando os mesmos tinham sido trazidos do campo $(47.4)$ ou criados em laboratório (24.5).

Freitas $^{*}$ (1973) obteve entre exemplares $B$. glabrata albinos. média de 98 ovos por desova e nos melânicos da mesma espécie 60 ovos por cápsula ovífera. Este excelente resultado foi conseguido graças ao emprego de uma técnica onde o autor utilizou uma ração especial e alface em quantidade adequada, oxigenação constante e água corrente nos aquários.

Nota-se, ainda. na Tabela 1 , que houve variação acentuada do número de ovos por desova em cada período, dentro de cada população estudada e em cada par de caramujos utilizados. Em $B$. glabrata a média oscilou entre 17,1 a 25,6 enquanto em $B$. tenagophila houve variação de 11,7 a 24,1 . Em ambas as espécies verificou-se maior fecundidade no mês de abril quando registraram-se temperaturas médias de $34,7^{\circ} \mathrm{C}$ para a máxima, $19,0^{\circ} \mathrm{C}$ para a mínima e $25^{\circ} \mathrm{C}$ para a temperatura da água.

Por outro lado. a Figura 1 mostra que as variaçōes referentes a oviposição foram muito maiores em $B$. tenagophila, durante os 11 períodos de observação.

Rey ${ }^{16}$ (1956) já havia notado variações no número de ovos, em cada postura, sendo que um mesmo animal pode ovipor seguidamente cápsulas muito pequenas e grandes sem que se saibam das causas desse comportamento. $\mathrm{O}$ autor encontrou média variando entre 9,4 a 22,7 ovos por cápsula ovífera em $B$. glabrata e 9,7 a 24,7 em $B$. tenagophila. A divergência de dados obtidos numa mesma cepa de planorbídeos foi mais uma vez comprovada em trabalhos realizados com B. glabrata de Salvador: Jansen ${ }^{*}$ (1944) obteve média de 45 ovos por desova e Barreto $^{1}$ (1960) entre 5 a 7,5. Os dados obtidos no presente trabalho situam- se entre esses dois extremos. Vale ressaltar, no entanto, que as diferentes técnicas empregadas em cada experiência podem provocar resultados diversos, numa mesma população.

O estudo comparado do número de ovos por desova em populações de espécies distintas foi realizado primeiramente por Jansen * (1944) que notou diferença considerável entre exemplares $B$. glabrata e $B$. straminea. Rey ${ }^{16}$ (1956) obteve maior número de ovos por desova em $B$. tenagophila do que em $B$. glabrata. Por outro lado, Magalhães \& cols., ${ }^{6,-}$ (1968 e 1969) obtiveram resultado inverso, quando comparou populaçōes de $B$. glabrata e $B$. tenagophila, encontrando diferença significativamente maior para a primeira espécie. Estes últimos dados foram concordantes com resultados desta experiência.

Além da diferença aparente entre a média do número de ovos por desova, de cada espécie encontrada. verificou-se, tamhém, diferença das médias em cada periodo, entre as duas populações. Esta observação analisada através do teste " $t$ " revelou que. com exceção dos períodos 1.2 e 9, o número de ovos por cápsula ovífera diferiu significativamente ao nível de $5 \%$. O teste evidenciou, também, que $B$. glabrata foi mais eficaz quanto ao parâmetro em questão. com exceção do primeiro período (Tabela 4). Portanto, $B$. glabrata mostrou-se mais fecundo que $B$. tenagophila.

Os fatores ambientes exerceram certa influência na oviposição pois, em geral, a média do número de ovos encontrada nas cápsulas oviferas foi maior em temperaturas mais altas. Entretanto, cálculos estatísticos mostraram a existência de fraca correlação entre a média de ovos por desova de $B$. glabrata e os fatores ambientes. Houve maior correlação entre a fecundidade de $B$. tenagophila e a temperatura máxima $(46.3 \%)$. Por outro lado, houve fraca correlação com a temperatura da água e com a pressão atmosférica. 
KAWAZOE, U. - Aiguns aspectos da biologia de Biomphalaria glabrata (Say, 1818) e Biomphalaria tenagophila (D'Orbigny, 1835) (Pulmonata, planorbidae). II - Fecundidade e fertilidade. Rev. Saude pübl., S. Paulo, 11:47-64, 1977.

Paulini \& Camey ${ }^{12}$ (1964) também notaram a influência da temperatura sohre a oviposição, obtendo melhor resultado quando mantere os animais a $25^{\circ} \mathrm{C}$.

Todos os trabalhos aqui citados contribuiram. de certo modo. para o conhecimento deste parâmetro. ainda que, para a comparação dos resultados seja necessário padronizar as técnicas utilizadas. Desse modo. deve-se levar em consideração diversos fatores que possam influir no fenômeno: tamanho dos moluscos, temperatura do ar, e principalmente da água. número de caramujos por frasco, volume de água dos aquários, alimentação, oxigenação da água, etc.

\subsubsection{Número de Ovos e Cápsulas Ouiferas por Caramujo}

Os resultados contidos na Tabela 4 , que apresentam observações realizadas em 11 períodos consecutivos. mostraram que $B$. glabrata apresentou, de um modo geral, maior fecundidade do que $B$. tenagophila. A análise estatística das médias do número de cápsulas ovíferas por caramujo, entre as duas populações aqui estudadas, revelou diferença significativa em 6 períodos e a relação apresentou-se praticamente igual nos períodos 5. 6, 9, 10 e 11 (Tabela 5). Deste modo, apesar dessa diferença ser mais favorável a $B$. glabrata, não se pode afirmar que esta espécie seja mais fecunda. sem efetuar novas observações em período mais longo.

Apenas Rey ${ }^{16}$ (1956) observou paralelamente a fecundidade de $B$. glabrata e $B$. tenagophila, adotando a relação cápsula ovífera/caramujo. Este autor não notou diferença significativa entre as médias dessas duas populações.

Entretanto, a comparação da fecundidade entre as duas populações aqui estudadas, em termos de número médio de ovos/caramujo, revelou diferença significativamente maior para $B$. glabrata em todos os períodos, exceto no 9. (Tabela 5 ). Portanto, as cápsulas oviferas das populaçōes de $B$. glabrata apresentaram maior quantidade de ovos do que em $B$. tenagophila.

A comparação de nossos dados com os resultados obtidos por outros autores só foi permitido mediante os resultados apresentados na Tabela 7 . onde foi considerado o número médio de cápsulas ovíferas e ovos por caramujo. efeluado em um dia.

Diversos autores verificaram a existência de grande variabilidade. trabalhando com diferentes espécies e populaçōes de planorbideos. Os melhores resultados foram obtidos por Ritchie \& cols. ${ }^{17}$ (1966) que conseguiram a média de 85 ovos por caramujo-dia e 1.7 desovas/caramujo-dia quando utilizaram um par de exemplares B. glabrata, cepa de Porto Rico.

O diâmetro dos moluscos e o tamanho dos lotes empregados em cada recipiente influiram na fecundidade, tal como ocorreu no item 4.1.1. Deste modo. em exemplares com diâmetros maiores, houve maior oviposição por caramujo-dia, como observou Pimentel ${ }^{15}$ (1957) que obteve média de 2.9 e 27,3 ovos/caramujo-dia em $B$. glabrata medindo 8,4 e $19,3 \mathrm{~mm}$ de diâmetro, respectivamente. Ritchie \& cols. ${ }^{1 i}$ (1966) assinalaram maior fecundidade quando colocaram um par de planorbídeos (85 ovos/caramujo-dia e 1,7 desovas/caramujo-dia), ao invés de deixá-los isolados (23 ovos/caramujo-dia e 0.6 desovas/caramujo-dia) ou agrupados em número de 5 ( 66 ovos/caramujo-dia e 1.4 desovas/caramujo-dia). Entretanto, Brumpt" (1941) encontrou para B. glabrata isolados e pareados 0.89 e 0.76 desovas/caramujo-dia, respectivamente, enquanto Perlowagora ${ }^{14}$ (1958) obteve média de 0.47 e 0.67 desovas/caramujo-dia em $B$. glabrata pareados e isolados, respectivamente. Estes dados mostraram maior fecundidade dos planorbídeos mantidos isolados, discordando dos resultados obtidos por Ritchie \& cols. ${ }^{1 i}$ (1966). 
KAWAZOE, U. - Alguns aspectos da biologia de Bromphalaria glabrata (Say, 1818) e Biom. phalaria tenagophila (Dorbigny, 1835) (Pulmonata, planorbidae). II - Fecundidade e fertilidade. Rev. Salude publ., S. Paulo, 11:47-64, 1977.

Os dados desta experiência foram concordantes apenas com os trabalhos de Perlowagora ${ }^{14}$ (1958) e Ritchie \& cols. ${ }^{1 *}$ (1966), apesar destes terem mantido exemplares $B$. glabrata isolados. Por outro lado, os resultados referentes a $B$. tenagophila apresentaram maior fecundidade do que os obtidos por Rey ${ }^{16}$ (1956) e Milward de Andrade \& Carvalho ${ }^{10}$ (1972). Estes autores provaram que a utilização de diferentes nutrientes influiam sobre a fecundidade dos planorbídeos. verificando que o emprego de alface + aquariol era mais eficiente que o uso de apenas alface ou aquariol. Obtiveram melhor resultado do que o nosso, utilizando o primeiro método.

O estudo do número de ovos por caramujo-dia entre as espécies $B$. glabrata e $B$. tenagophila foi realizado inicialmente por Rey ${ }^{16}$ (1956) que não notou diferença entre as duas populações. No entanto, Magalhães \& cols. ${ }^{6, \tau}(1968$ e 1969) verificaram diferença significativa entre as espécies, com $B$. glabrata apresentando maior fecundidade. Nossos dados concordaram com os resultados obtidos por Magalhães \& cols. apesar destes autores terem assinalado menor fecundidade em ambas as espécies.

A influência dos fatores ambientes sobre a fecundidade de $B$. glabrata e $B$. teragophila foi testada através de cálculos estatísticos revelando que $B$. glabrata apresentou fraca correlação com os referidos fatores, verificando-se o mesmo em $B$. tenagophila, exceto em relação a temperatura máxima $(45 \%$ de correlação). Este fato vem confirmar o que foi ohservado no item anterior de que há preferência dos caramujos em ovipor nas temperaturas mais quentes. Paulini \& Camey ${ }^{12}$ (1964) verificaram que havia maior oviposição a temperatura de $25^{\circ} \mathrm{C}(0,9$ desovas/caramujo-dia) do que entre $15-25^{\circ} \mathrm{C}$ 10,5 desovas/caramujo-dia) ou a $15^{\circ} \mathrm{C}$ (0.1 desova/caramujo-dia). confirmando, assim. a influência da temperatura sobre a oviposição.

Os fatos acima mostraram que houve maior variação do número de ovos por caramujo do que do número de desovas por caramujo, além de $B$. glabrata apresentar. em média, maior número de ovos por cápsula ovífera e consequentemente ser mais fecunda do que a outra espécie aqui estudada.

\subsection{Fertilidade}

Obtivemos taxa elevada de eclosão nas duas populaçōes com a média de $94.8 \%$ e $90.5 \%$ em B. glabrata e B. tenagophila. respectivamente (Tabela 8 ). Esses dados estão de acordo com resultados obtidos por Penido \& cols. ${ }^{1 s}$ (1951) que encontraram $91.2 \%$ de eclosão em B. glabrata vindos do campo porém. nos exemplares criados em laboratório, $40,3 \%$ dos caramujos não eclodiram. Por outro lado. Paraense ${ }^{11}$ (1955) encontrou $78,3 \%$ de eclosão em desovas de $B$. glabrata obtidas por auto-fecundação. Resultado semelhante foi registrado por Pimentel ${ }^{15}$ (1957). Freitas $^{3}$ (1973) conseguiu fertilidade de $99.0 \%$ empregando exemplares albinos de $B$. glabrata.

Apesar da alta taxa de fertilidade registrada em ambas as espécies aqui estudadas, verificou-se variações em cada período, com taxas mais altas nos meses de novembro a janeiro $(98.2 \%)$ e taxas mais baixas nos meses de abril-maio $(87.6 \%)$ em $B$. glabrata. Os exemplares $B$. tenagophila alcançaram taxas mais altas em outubro-novembro $(95,0 \%)$ e mais baixas em abril-maio $(85,7 \%)$. A Fiqura 3 mostrou coincidência nas duas populaçōes quanto a época de menor fertilidade (abril-maio), porém, torna-se difícil a determinação da época mais fértil. Não se verificou ritmo sazonal em relação à fertilidade e a temperatura parece ter influído pouco na eclosão dos caramujos. Este fato foi confirmado pelos cálculos estatísticos que revelaram fraca 
KAWAZOE, U. - Alguns aspectos da biologia de Biomphalaria glabrata (Say, 1818) e Bıomphalaria tenagophila (D'Orbigny, 1835) (Pulmonata, planorbidae). II - Fecundidade e fertilidade. Rev. Saúde públ., S. Paulo, 11:47-64, 1977.

correlação entre as temperaturas e as taxas de eclosão de $B$. glabrata. $O$ coeficiente de correlação foi um pouco mais elevado em relação a $B$. tenagophila $(29,0 \%)$.

Esses resultados estão de acordo com os obtidos por Michelson" (1961) que também não encontrou relação entre taxa de eclosão e temperatura pois obteve em B. glabrata de Porto Rico, 73 e $79 \%$ de eclosão a temperatura de $25^{\circ}$ e $30^{\circ} \mathrm{C}$, respectivamente. Sturrock \& Sturrock ${ }^{1 \times}$ 1 1972) também citam a pequena influência da temperatura sobre a taxa de eclosão quando encontraram $86 \%$ de eclosão a $20^{\circ} \mathrm{C}$ e $95 \%$ tanto a $25^{\circ}$ como a $30^{\circ} \mathrm{C}$.

Porém, os nossos resultados não estão de acordo com os obtidos por Rey ${ }^{16}$ 11956) que verificou grande variação na fertilidade dos ovos conforme os lotes empregados e a época do ano. Deste modo, em B. glabrata de Ipauçu obteve $56 \%$ e $37,7 \%$ de eclosão nos meses de março e abril, respectivamente. O lote de Jacarezinho apresentou $64,5 \%$ de eclosão em fevereiro e de Itaporanga, média de $72,4 \%$ entre janeiro a dezembro. Para $B$. glabrata de Aracajú foram registradas variações de $78,8 \%$ a $100 \%$ entre os meses de maio a julho. Em exemplares $B$. tenagophila de Ana Dias houve 69,9\% de eclosão, de fevereiro a setembro. Numa das experiências, Rey verificou a fertilidade dos planorbideos mês por mês, deixando hem claro sua variabilidade com relação as épocas do ano. Falam no mesmo sentido as experiências realizadas com B. tenagophila de Ana Dias, entre janeiro a agosto do mesmo ano. De fevereiro a agosto para moluscos $B$. glabrata de Itaporanga d'Ajuda e de fevereiro a junho para os de Ana Dias (exceto maio), a percentagem de eclosão permaneceu em nível alto, caindo hastante nos meses seguintes. Os caramujos B. glabrata de Itaporanga apresentaram acentuada baixa de fertilidade a partir de setembro, caindo até zero em novembro, para elevar-se novamente em dezembro, $O$ autor concluiu pela existência de um ritmo periódico de multiplicação dos planorbídeos, havendo uma época favorável que abrange aproximadamente o primeiro semestre do ano, com maior número de ovos e desovas, maior tamanho destas, redução das posturas estéreis e aumento geral da taxa de eclosão.

Perlowagora ${ }^{11}$ (1958) sugeriu que a flutuação na eclosão de caramujos dentro de uma "geração individual" estava associada com a incidência de ovos não viáveis. Por outro lado, notou que a percentagem de ovos não eclodidos em desovas férteis era baixa: 5,5 a $10 \% \mathrm{em}$ espécimes acasalados e 5,6 a $7,0 \%$ nos isolados. Isso significaria que se as desovas estéreis estivessem incluídas em grupos usados na determinação da taxa de eclosão, teria alcançado índice de 90 a $95 \%$. Observou, também, que o decréscimo na taxa de eclosão era evidente com o advento do "tempo frio". No entanto. concluiu que não havia evidência de um ritmo sazonal na variedade dos ovos, e nem na taxa de eclosão. Assim, em estudo comparado de duas populaçóes $F$ e $F x$, realizado durante um ano, verificou que na população $F$ a taxa mais alta de eclosão foi no mês de fevereiro $(85,2 \%)$ e as mais baixas nos meses de outubro a fevereiro. Na população $F x$ a taxa mais alta de eclosão verificou-se em setembro $(91.5 \%)$ e a mais haixa em fevereiro $(62.5 \%)$.

A comparação das taxas de eclosão entre $B$. glabrata e $B$. tenagophila obtidas. mostrou que a primeira espécie apresentou sempre taxas mais elevadas do que a segunda, com exceção do primeiro período. Esse fato foi confirmado pelo "teste de igualdade de duas proporçōes" que revelou diferença significativa entre as médias das duas populações, em cada período, exceto no $7 .^{\circ}$, sugerindo ser $B$. glabrata mais fértil que $B$, tenagophila.

No entanto, Magalhães \& De Lucca ${ }^{3}$ (1971), apesar de terem obtido taxas altas 
KAWAZOE, U. - Alguns aspectos da biologla de Biomphalaria glabrata (Say, 1818) e Biomphalaria tenagophlla (D'Orbigny, 1835) (Pulmonata, planorbidae). II — Fecundidade $e$ fertilidade. Ret. Saide pübl., S Paulo, 11:47-64, 1977.

na riabilidade dos ovos. tanto para $B$. glabrata $(91.6 \%)$ como para $B$. tenagophila $(92.4 \%)$. não encontraram diferença significativa entre os percentuais. quando analisados estatisticamente. 0 fato dessa ohservação ter sido realizada no mesmo local em que se realizou o nosso trabalho e em condiçōes semelhantes, deve ter contribuido na semelhança dos resultados referente ao elevado percentual ohtidos.

A presença de ovos estéreis em alğumas desovas mostrou nāo afetar a taxa de eclosão dos caramujos pois em nosso trabalho foi encontrada variação de 0.1 a $0.9 \%$ em $B$. glabrata e 0.1 a $2.1 \%$ em $B$. tenagophila, sendo este percentual considerado muito haixo. Em ambas as espécies a fertilidade foi praticamente a mesma: $99.5 \%$ e $99.4 \%$. No entanto. a espécie $B$. glabrata apresentou menor número de ovos estéreis do que a outra espécie estudada. Esses dados estão de acordo com as observações de Rey ${ }^{1 "}$ 11956) que encontrou ovos estéreis em cápsulas oviferas férteis. sempre com ta- sa muito reduzida: a variação em $B$. glabrata foi de 0 a $2.7 \%$ e para $B$. tenagophila de 0.18 a $2.0 \%$. No entanto. apontou como principal causa na variação da fertilidade dos ovos. o encontro de desovas totalmente estéreis em moluscos que permaneceram isolados ou agrupados. Jestes. a percentagem de cápsulas ovíferas estéreis variou de 31.3 a $62.5 \%$ e entre os isolados foi de $40.0 \%$. Esse fato não foi aqui registrado onde a percentagem de cápsulas ovíferas estéreis. em ambas as populações. foi menor que a obtida para ovos estéreis. Notou-se. por outro lado. que a esterilidade dos ovos não sofria influência dos fatores ambientes. sendo esse fato confirmado pela análise da matriz de correlação entre os fatores.

A G R A D E C I I E N T OS

Ao Dr. Luiz Augusto Magalhães pela orientação do trabalho e ao Prof. José Ferreira de Carvalho pela análise estatística dos dados.

RSPU-B/338

KaWAzoE, U. (Some biological aspects of Biomphalaria glabrata (Say, 1818) and Biomphalaria tenagophila (D'Orbigny, 18.35) (Pulmonate, planorbidae). II - Fecundity and fertility I Rev. Saúde públ,, S. Paulo, 11:47-64, 1977.

ABSTRACTs: The fecundity (ratio egg-masses per snail, eggs per snail and eggs per egg-mass) and the fertulity (hatchability and vabulty of eggs) of Biomphalaria glabrata and Biomphalaria tenagophila were compared during one year, in the laboratory. The alerage of eggs per egg-mass was significantly higher in B. glabrata (19 9) than in B. tenagophila (16.2) and both species showed highest fecundity during April. The influence of temperature was very small. The fecundity defined as egg-mass per snal per day was greater in B. glabrata $(0.65)$ than in B. tenagophila $(0.56)$. The same was lerified in the ratio eggs per snal per day: the average was $1.3 .4 \mathrm{~m} \mathrm{~B}$. glabrata and 9.9 in B. tenagophila. Considering the fertlity as percentage of snail hatchability, B. glabrata showed an averuge of 95.8 and B. tenagophila $90.5 \%$, the difference being significant. at the $5 \%$ level. The greatest hatchabiluty rate in B. glabrata was observed during November-January $(980)$; in B. tenagophila, during October-November 195.0\%). Seasonal rhythm and influence of seasonal variation of temperature were not observed

Uniterms: Planorbidae, biology. Biomphalaria glabrata. Biomphalaria tenagophila. Fecundity. Fertiluty 
KAWAZOE, U. - Alguns aspectos da biologia de Biomphalaria glabrata (Say, 1818) e Biomphalaria tenagophila (D'Orbigny, 1835) (Pulmonata, planorbidae). II — Fecundidade e fertilidade. Rev. Saúde pübl., S. Paulo, 11:47-64, 1977.

\section{REFERENCIAS BIBLIOGRÁFICAS}

1. BARRETO, A.C. - Esquistossomose mansônica na cidade de Salvador. Estudo do vetor, relação parasitohospedeiro e aspectos epidemiológ1. cos. Bol. Fund. G. Moniz, 16:1-80. 1960.

2. BRUMPT, E. -- Observations biologiques diverses concernant Planorbis (Aus tralorbis) glabratus hote intermédiaire de Schistosoma manson!. Ann. Parasitol., 18:9-45, 1941.

3. FREITAS, J.R. - Ritmo de crescimento da Biomphalaria glabrata (Say 1818). Padronização da técnica dé criação. Belo Horizonte, 1973. [Tese de Doutoramento].

4. JANSEN, G. - Sobre a validade do Australorbis centimetralis (Lutz, 1918). Mem. Inst. Osualdo Crus, 40: 201-9, 1944

5. KAWAZOE, U. - Alguns aspectos da b.ologia de Biomphalaria glabrata (Say, 1818) e Blomphalaria tenayophila (d'Orbigny, 1835) (Pulmonata. Planorbidae). I - Duração do período embrionário. Rev. Saude públ. S. Paulo, 10:57-64, 1976

6. MAGALHÃES, L.A. et al. - Estudo da dinâmica populacional de $B 10 \mathrm{~m}$. phalaria glabrata e $B$. tenagophila. I - Estudo comparativo da postura e do desenvolvimento das desovas de populações de Blomphalaria glabrata e $B$. tenagophila. Nota prévia. Rev. paul. Med., ræ:268-9. 1968.

7. MagalHAES, L.A. \& CaRValho, J.F - Estudo da postura de duas populações de planorbídeos. Rev. Soc. bras. Med. trop., 3:245-7, 1969.

8. MAGALHAES, L.A. \& DE LUCCA, O. - Determinação do periodo de desenvolvimento e da viabilidade das desovas de duas populações de Biomphalaria glabrata e Biomphalaria te. nagophila. (Mollusca, Planorbidae). Rev. Soc. bras. Med. trop. 5:30713, 1971 .

9. MICHELSON, E.H. - The effect of temperature on growth and reproduction of Australorbis glabratus in the laboratory. Amer. J. Hyg., 73 : $66-74,1961$
10. MILWARD DE ANDRADE, R. \& CARVALHO, O.S. - Alimentacāo de planorbídeos criados em laboratório. I - Biomphalaria tenagophila (d'Orbigny, 1835), Rev. bras, Biol.: 32: $225-33,1972$.

11. PARAENSE, W.L. - Autofecundaçāo e fecundação cruzada em Australorbis glabratus. Mem. Inst. Osualdo Crus $53: 277-84,1955$.

12. PAUlini, E. \& CAMEY, T. - Observaçôes sobre a biologia do $A$. gla. bratus. II - Influencia da temperatura do ambiente sobre a freqüência da postura. Rev. bras. $M a$ lar., 16:499-504, 1964.

13. PENIDO, H.M. et al. - Observacões sobre as posturas e o tempo de evolução de duas espécies de caramujos encontrados no Vale do Rio Doce. Rev. Serv. Saude públ., Rio de Janeiro, 4:407-12, 1951.

14. PERLOWAGORA, S.A. - Studies on the biology of Australorbis glabratus schistosoma-bearing brazilian snail. Rev. bras. Malar. 10:459-529, 1958.

15. PIMENTEL, D. - Life history of Australorbis glabratus the intermediate snail host of Schistosoma mansoni in Puerto Rico. Ecology, 38:576-80 1957.

16. REY, L. - Contribuição para o comportamento da morfologia, biologia e ecologia dos planorbideos brasileiros transmissores da esquistossomose. Rio de Janeiro, Servico Nacional de Educação Sanitária, 1956.

17. RITCHIE, L.S. et al. - Biological potentials of Australorbis glabratus. Life span and reproduction. Amer. J. trop. Med. Hyg. 15:614.7, 1966.

18. STURROCK, R.F. \& STURROCK, B.M. - The influence of temperature on the biology of Bromphalaria glabrata (Say), intermediate host of Schistosoma mansonl on St. Lucia, West Indies. Ann. trop. Med. Parasitol. $66: 385-90.1972$

Recebido para publicastio em 19/0r:1976 Aprovado para publicacio em 10 09/1976 